\title{
The effects of SILO \& AWRA wind speeds on irrigation depth simulations
}

\author{
$\underline{\text { David Bretreger }}^{\mathrm{a}}$ (i) and In-Young Yeo ${ }^{\mathrm{a}}$ (i) \\ ${ }^{a}$ School of Engineering, The University of Newcastle, Newcastle, NSW \\ Email: david.bretreger@uon.edu.au
}

\begin{abstract}
The availability of meteorological data can be sparse across Australia, particularly in regional areas, leading to the use of gridded products. Available gridded products range from measured data such as precipitation and temperature to derived variables such as the various techniques used to describe evapotranspiration (ET). The lack of automatic weather stations that provide ET, compared to numbers of rain gauges, means these gridded ET products are potentially of more value due to the large distances between users and the nearest observation.
\end{abstract}

Gridded data is currently available through the Scientific Information for Land Owners (SILO) service as well as through the Australian Water Resources Assessment Landscape (AWRA) model and datasets from the Australian Water Availability Project (AWAP). These services provide grids for many variables used in hydrology and its related fields. The AWAP and SILO products have previously been compared although they predominately focused on the differences between the rainfall variables and interpolation methods. Another key difference between the products, that relates to this paper, is that AWRA uses a climatologically derived wind speed in its ET calculations, whereas SILO assumes a speed of $2 \mathrm{~m} / \mathrm{s}$. Using a varying wind speed has been found to be an important factor in semi-arid regions when looking at crop water use, this may be particularly relevant in agricultural regions of Australia. Only the precipitation $(\mathrm{P})$ and reference crop ET $\left(E T_{0}\right)$ product variables will be used in this paper.

The paper describes the comparison of using the two available products as inputs to interact with the remote sensing observations obtained from Digital Earth Australia. The $\mathrm{P}$ and $E T_{0}$ are predominate drivers in the method. The AET is found using the methods outlined in FAO56, although the crop coefficients are derived from remote sensing observations. The simulations were performed over four sites, this includes an almond orchard, two vineyards and a cotton farm. The results show that for annual simulations, there were only small differences between the two products, although the AWRA methods produced smaller standard deviations. The $2 \mathrm{~m} / \mathrm{s}$ wind speed assumed in the SILO calculation was found to be much lower than the local statistical averages at nearby gauge sites. This led to the AWRA and SILO products deviating during summer, when higher winds are causing higher ET values, which is not accounted for in the SILO dataset.

This paper aims to give an indication of the possible implementations for farmers or natural resource managers may see due to changing their systems from SILO to the technically improved AWRA product. It may also provide additional insight into how further research may be impacted by choosing one of the gridded products over the other. The current results indicate that the technical improvements implemented in AWRA are providing slight improvements in irrigation simulations. This may encourage natural resource managers to alter their methods to achieve better results for their specific scenario.

Keywords: SILO, AWRA, irrigation, wind speed, evapotranspiration 


\section{INTRODUCTION}

Gridded products are used in many modelling scenarios over Australia, and the world. The lack of missing data experienced with gauging station time series and the spatial coverage of gridded data makes it particularly appealing. The gridded data available ranges from measured data like precipitation and temperature to derived variables such as the various evapotranspiration methods. Although there are potential issues with using these products that users need to be aware of (Tozer et al., 2012). Although there are currently only 486 automatic weather station sites across Australia that publish reference evapotranspiration (Frost et al., 2017), meaning many farmers are likely relying on data collected hundreds of kilometres away or using gridded data, despite its limitations, for their farm management duties.

The two main gridded products available in Australia are available from the Queensland Government through their Scientific Information for Land Owners (SILO) service (Jeffrey et al., 2001) or from the Bureau of Meteorology (BoM)'s Australian Water Availability Project (AWAP) (Jones et al., 2009) or Australian Water Resources Assessment Landscape model (AWRA) (Frost et al., 2018) products. Despite these services providing products for many variables, comparisons thus far have been limited to rainfall (Beesley et al., 2009; Tozer et al., 2012), which is largely different due to interpolation techniques.

Many of the additional products, such as the reference evapotranspiration, are reliant on a large number of climatic variables for their calculation. The differences between the SILO and AWRA products are subtle but there are many. A clear difference, and a focus of this paper, is the limitation of the SILO $E T_{0}$ dataset in that it assumes a $2 \mathrm{~m} / \mathrm{s}$ wind speed (Frost et al., 2017; SILO, 2016), whereas AWRA v6 has climate derived values (Frost et al., 2018). The $2 \mathrm{~m} / \mathrm{s}$ value is recommended by Allen et al. (1998) when no measured or local average values are available, although Jabloun and Sahli (2008) stated that local annual average values will perform better than this and Córdova et al. (2015) states that having a varying wind speed is particularly important in semi-arid areas when using the FAO Penman-Monteith equation. The large proportion of Australia that is classified as arid or semi-arid and subject to irrigation (i.e. the Murray Darling Basin) should mean that a varying wind speed is important to calculations.

As the SILO product has been available for longer than the AWRA $E T_{0}$, it is likely to have a larger user base despite the theoretically superior product. Examples of this include the IrriSat Irrigation Scheduling Application that uses either nearest gauge data, which is subject to the lack of gauge density, or the SILO gridded $E T_{0}$ (Hornbuckle et al., 2016b).

This paper aims to discover how the two major gridded climate products in Australia perform in a method used to assess irrigation water use with remote sensing observations. This will directly act as a guide on the future direction, and product to use, for the method tested when scaling to larger regions. Additionally, the outcomes of this paper may act as a guide for other users, such as individual farm managers and water resource managers/researchers who may be considering switching between the SILO and AWRA products and are unsure of the differences and the potential outcomes to their work and services.

\section{METHOD}

The methodology follows previously published work, calculating irrigation depth on a monthly time scale as per Bretreger et al. (2019). This method calculates the irrigation depth on a monthly scale. To do this it makes assumptions about a natural water balance with anthropogenic influences which results in negligible runoff and deep drainage, while also assuming soil moisture remains constant, avoiding plant water stress. This results in the following equation for irrigation depth:

$\operatorname{Irr}=A E T-P$

where $\operatorname{Irr}$ is the irrigation depth $(\mathrm{mm}), A E T$ is the actual evapotranspiration $(\mathrm{mm})$ and $P$ is the precipitation (mm). The AET is calculated via the approach outlined in FAO56 (Allen et al., 1998):

$A E T=E T_{0} \times K_{c}$

where $A E T$ is the actual evapotranspiration $(\mathrm{mm}), E T_{0}$ is the reference evapotranspiration $(\mathrm{mm})$ and $K_{c}$ is the crop coefficient. The $E T_{0}$ used for each of the locations is different based on the crop type, as discussed briefly in Section 3.3. There are two remote sensing relationships tested for this study. First is the equation used in the IrriSat Irrigation Scheduling Application (https://irrisat-cloud.appspot.com/) (Hornbuckle et al., 2016a; Hornbuckle et al., 2016b). This was originally derived over a range of crops by Trout and Johnson (2007). The relationship as defined by Hornbuckle et al. (2016a) is: 
$K_{c}=1.37 \times N D V I-0.086$

where NDVI is the normalized differential vegetation index (Rouse et al., 1974). This method will be referred to as Irri for this paper. An alternative method derived by Kamble et al. (2013) which was also derived over a range of crop types is used as a comparison which is defined by:

$K_{c}=1.4571 \times N D V I-0.1725$

where NDVI is the normalized differential vegetation index. A 0.7 factor multiplier is applied to these relationships when simulating the wine grapes 1 field as there is evidence of plastic mulching (Pitt et al., 2015) as recommended by Allen et al. (1998).

To compare the results from each of the methods, the root mean square error (RMSE) was calculated for monthly and summed annual values. Additionally, the ratio of estimated to actual irrigation is calculated for annual values, with a value of 1 meaning the simulation is averaging the correct value. As two remote sensing methods are tested, a total of four outputs for each location will be compared.

\section{LOCATION \& DATA}

\subsection{Study Locations}

Four farm scale sites were assessed for this study. They include; an almond plantation, two vineyards and a cotton farm, details of these sites can be found in Table 1 . The almond and wine grapes 1 field both contain data for monthly irrigation values, whereas the wine grapes 2 and cotton fields only have annual data recorded. The annual average irrigation depths recorded for the almond, wine grapes 1 and 2 and the cotton farm are $923 \mathrm{~mm}, 139 \mathrm{~mm}, 281 \mathrm{~mm}$ and $363 \mathrm{~mm}$ respectively. Each of these sites is farmed under monoculture conditions. As monthly data is only available for the almond and wine grapes 1 field, only their monthly time series will be presented and compared.

Table 1. Details and locations of study sites

\begin{tabular}{|c|c|c|c|c|c|}
\hline Crop & Location & $\begin{array}{l}\text { Length of } \\
\text { Data }\end{array}$ & $\begin{array}{l}\text { Latitude, } \\
\text { Longitude }\end{array}$ & Area (ha) & Reference \\
\hline Almond & $\begin{array}{l}\text { Northern Adelaide } \\
\text { Plains, SA }\end{array}$ & $\begin{array}{c}\text { July } 2013- \\
\text { June } 2016\end{array}$ & $\begin{array}{l}-34.628^{\circ} \\
138.683^{\circ}\end{array}$ & 3.5 & $\begin{array}{l}\text { (Pitt et al., } \\
\text { 2015) }\end{array}$ \\
\hline $\begin{array}{l}\text { Wine } \\
\text { grape } 1\end{array}$ & $\begin{array}{l}\text { McLaren Vale wine } \\
\text { region, } \mathrm{SA}\end{array}$ & $\begin{array}{l}\text { July } 2011- \\
\text { June } 2015\end{array}$ & $\begin{array}{l}-35.239^{\circ} \\
138.523^{\circ}\end{array}$ & 28 & $\begin{array}{l}\text { (Pitt et al., } \\
\text { 2015) }\end{array}$ \\
\hline $\begin{array}{l}\text { Wine } \\
\text { grape } 2\end{array}$ & Waikerie, SA & $\begin{array}{l}\text { July } 2010- \\
\text { June } 2012\end{array}$ & $\begin{array}{l}-34.080^{\circ} \\
139.870^{\circ}\end{array}$ & 6.6 & $\begin{array}{l}\text { (Phogat et } \\
\text { al., 2017) }\end{array}$ \\
\hline Cotton & Emerald, QLD & $\begin{array}{c}\text { July } 2007- \\
\text { June } 2012\end{array}$ & $\begin{array}{l}-23.473^{\circ} \\
148.331^{\circ}\end{array}$ & 4.8 & $\begin{array}{l}\text { (Pendergast } \\
\text { et al., 2013) }\end{array}$ \\
\hline
\end{tabular}

\subsection{Remote Sensing Observations}

The remote sensing data comprises of the red and near-infrared bands of the Landsat series of satellites, ranging from Landsat 5, 7 and 8 depending on the sites observation data length. The 16 day revisit time of each satellite when combined provides an approximate weekly temporal resolution, which is averaged monthly. The satellite images were loaded from Digital Earth Australia (DEA) (Dhu et al., 2017) (http://geoscienceaustralia.github.io/digitalearthau/index.html). Digital Earth Australia provides the Landsat images with a $25 \mathrm{~m} \times 25 \mathrm{~m}$ resolution, which have been put through the built in correction, process and have pixel quality masking for cloud and shadow interference.

\subsection{Meteorological Data}

The meteorological data used in this study comes from two sources. The published products, although contain the same variables, have different values for the same time period. This is due to the many different techniques and assumptions used in the product derivation. The variables used in this paper are limited to the precipitation $(\mathrm{P})$ and the reference evapotranspiration $\left(E T_{0}\right)$. The two products are download from SILO (https://silo.longpaddock.qld.gov.au/) (Jeffrey et al., 2001) and from the BoM Australian Landscape Water Balance website (http://www.bom.gov.au/water/landscape/) which delivers data from AWRA; v6 is used in this paper (Frost et al., 2018). Both of these services deliver their products on a $0.05^{\circ}$ grid (approximately $5 \mathrm{~km}$ ). 
The input data for AWRA is the AWAP datasets (Jones et al., 2009), and as such the AWRA rainfall is treated as the AWAP rainfall. The main differences associated with the AWAP and SILO rainfall datasets arises from their interpolation methods, which is detailed in depth in their original and comparison publications (Beesley et al., 2009; Tozer et al., 2012). The interpolation differences effects all products provided by AWRA/AWAP and SILO. The papers by Tozer et al. (2012) and Beesley et al. (2009) do direct comparisons with gauge rainfall data not included in the datasets used for product production.

The $E T_{0}$ is used in two forms, the original FAO56 (short) and the ASCE (tall) variations. The $E T_{0}$ is defined by the Penman-Monteith equation specified by Allen et al. (1998) as:

$E T_{o}=\frac{0.408 \Delta\left(R_{n}-G\right)+\gamma \frac{C_{n}}{T+273} u_{2}\left(e_{s}-e_{a}\right)}{\Delta+\gamma\left(1+C_{d} u_{2}\right)}$

where; $\mathrm{ET}_{o}$ is the reference evapotranspiration (mm/day), $\Delta$ is the slope of the vapour pressure curve $\left(\mathrm{kPa} /{ }^{\circ} \mathrm{C}\right)$, $R_{n}$ is the net radiation at the crop surface $\left(\mathrm{MJ} / \mathrm{m}^{2} /\right.$ day $), G$ is the soil heat flux density $\left(\mathrm{MJ} / \mathrm{m}^{2} /\right.$ day $), \gamma$ is the psychometric constant $\left(\mathrm{kPa} /{ }^{\circ} \mathrm{C}\right), T$ is the mean daily air temperature at $2 \mathrm{~m}$ height $\left({ }^{\circ} \mathrm{C}\right), u_{2}$ is the wind speed at a height of $2 \mathrm{~m}(\mathrm{~m} / \mathrm{s}), e_{s}$ is the saturation vapour pressure $(\mathrm{kPa}), e_{a}$ is the actual vapour pressure $(\mathrm{kPa}), C_{n}$ is a constant that is a function of the time step and aerodynamic resistance, $C_{d}$ is a constant that is a function of the time step, bulk surface resistance and aerodynamic roughness.

The $C_{n}$ and $C_{d}$ values vary between the FAO56 and ASCE methods. The values for FAO56 are 900 and 0.34 for $C_{n}$ and $C_{d}$, respectively which corresponds to a grass reference crop. While for the ASCE calculation the values of $C_{n}$ and $C_{d}$ are 1600 and 0.38 , respectively which is for an alfalfa reference crop. These values are changed to account for the differences that would be seen when comparing the vegetation properties and responses during transpiration. The products used in this study are computed over a daily time step, and as such typical assumptions such as a negligible soil heat flux $(G)$ are applied to this product. The almond field is simulated with the ASCE $E T_{o}$, the other three fields are simulated using the FAO56 ET (Bretreger et al., 2018; Bretreger et al., 2019).

The SILO $E T_{0}$ products show a clear limitation in that they do not use climatologically derived wind speed, rather it assumes a wind speed of $2 \mathrm{~m} / \mathrm{s}$ (Frost et al., 2017; SILO, 2016). Whereas the recent update to AWRA v6 (Frost and Wright, 2018) included the $E T_{0}$ products with climatologically derived wind speeds as per the work by McVicar et al. (2008) (Frost et al., 2017; Frost et al., 2018). It also included additional updates not specifically related to this paper (Frost and Wright, 2018) and hence are not discussed. It is worth noting that the SILO dataset covers a longer historical timeframe which may be of benefit to some users.

\section{RESULTS \& DISCUSSION}

The time series presented in Figure 1 show that there is limited difference noticeable by visual inspection to the irrigation simulation for both the almond and wine grapes 1 fields. The biggest differences occur at the maximums (summer) where the two AWRA and two SILO simulations each separate with SILO generally being the lower estimation. The slight differences seen throughout may be attributed to the slightly different derivation techniques used by the data providers.

The larger differences are thought to be due to the climate derived wind speed. As the method calculates the irrigation as the difference between the AET and $\mathrm{P}$, the maximum irrigation events are predominately occurring during high AET (and low P), while the opposite is true for minimum events. Events like this are driven by a variety of climatic factors including wind speed.

The statistical wind speeds available from the BoM for monthly and yearly averages at 9 am and 3 pm from nearby stations is predominately well above the $2 \mathrm{~m} / \mathrm{s}$ assumed in the SILO methodology (wind statistics available from http://www.bom.gov.au/climate/data/). The stations that recorded this data for the almond (ID 023083), wine grapes 1 (ID 023885) and cotton (ID 035264) locations indicate that $2 \mathrm{~m} / \mathrm{s}$ is a vast underestimation with annual averages between 4 and $6 \mathrm{~m} / \mathrm{s}$, and no individual months below $3 \mathrm{~m} / \mathrm{s}$. The wine grapes 2 (ID 020028) location shows winter months below $2 \mathrm{~m} / \mathrm{s}$ while summer increases, leading to annual average wind speeds reported at $2.36 \mathrm{~m} / \mathrm{s}$ at 9 am and $3.39 \mathrm{~m} / \mathrm{s}$ at $3 \mathrm{pm}$. All stations showed agreement on higher wind speeds during the summer months, corresponding with simulation outputs showing higher irrigation/AET values. As the values compared are statistical averages, it does not account for unusual events, but it gives an indication of the possible issues with assumed wine speeds. It is likely the climate derived wind speed of AWRA is more representative of the conditions seen on site than the assumed constant $2 \mathrm{~m} / \mathrm{s}$ used in the SILO derivation. These sites are located in semi-arid to arid locations which agrees with the findings of Córdova et al. (2015), that wind speed is an important factor in regions with this classification. 

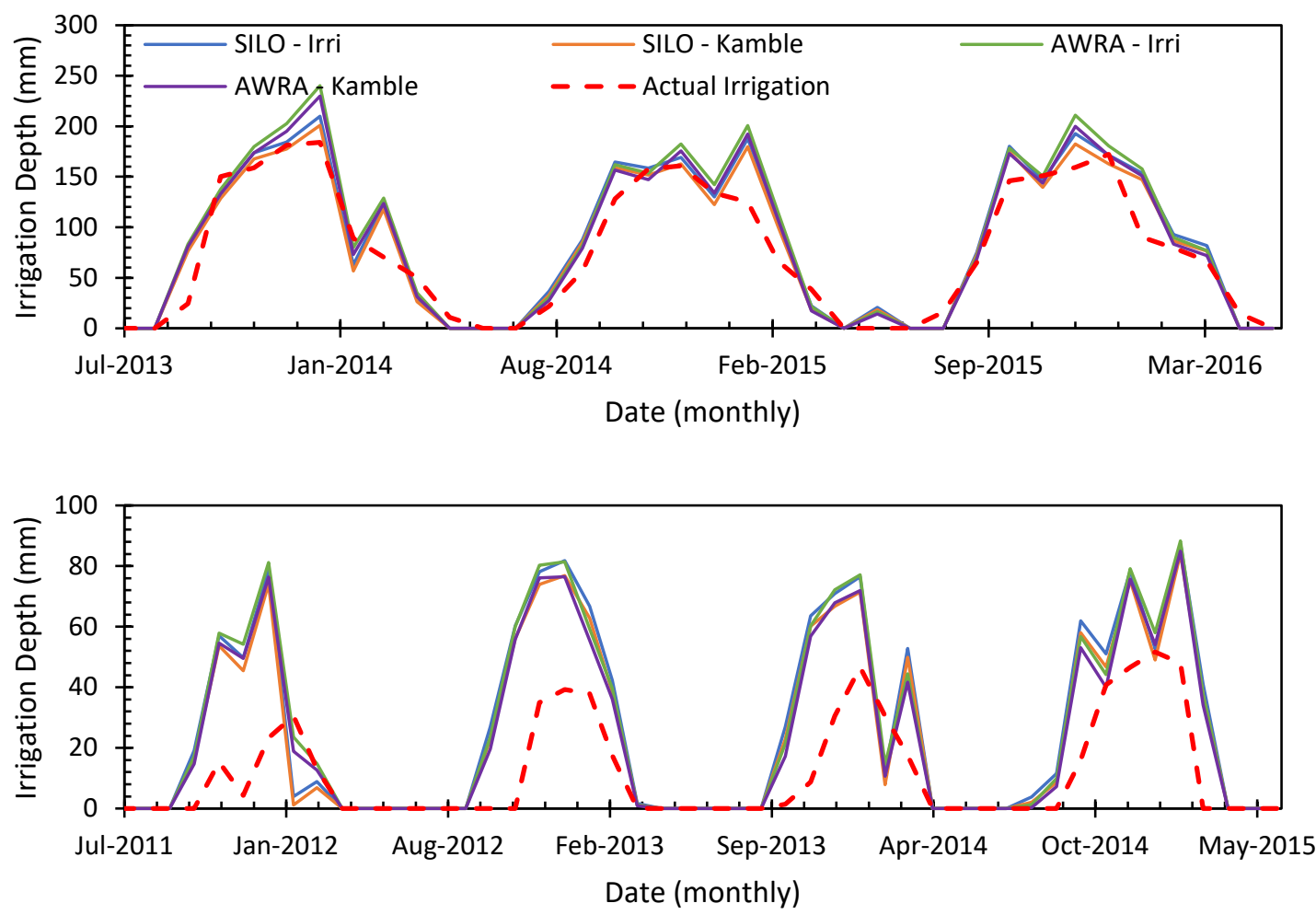

Figure 1. Irrigation simulation and observed time series for almond (top) and wine grape 1 (bottom)

a)

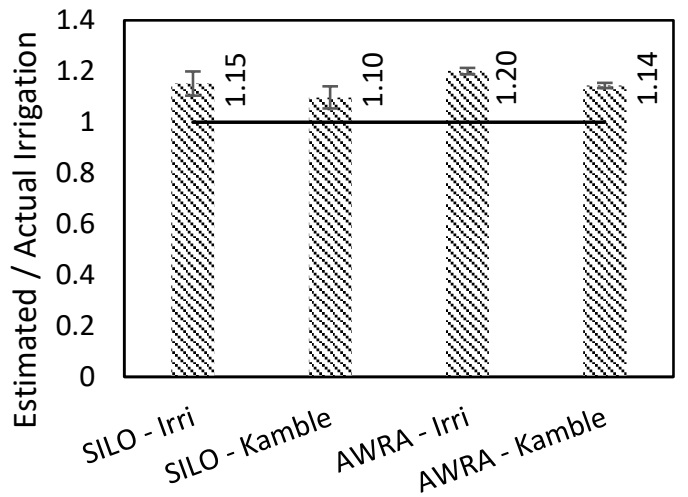

c)

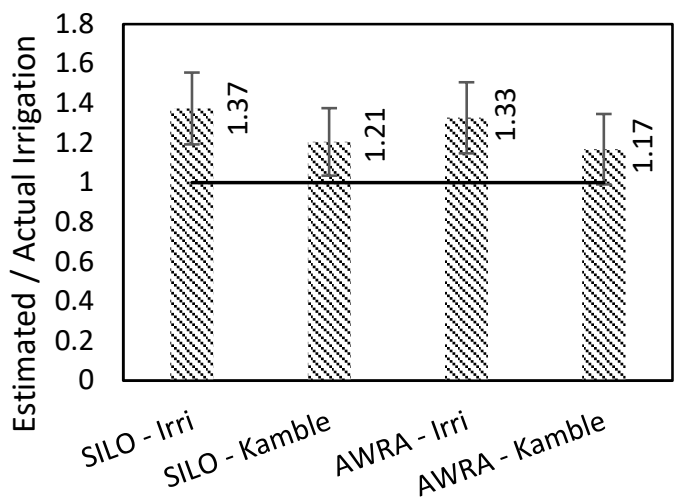

b)

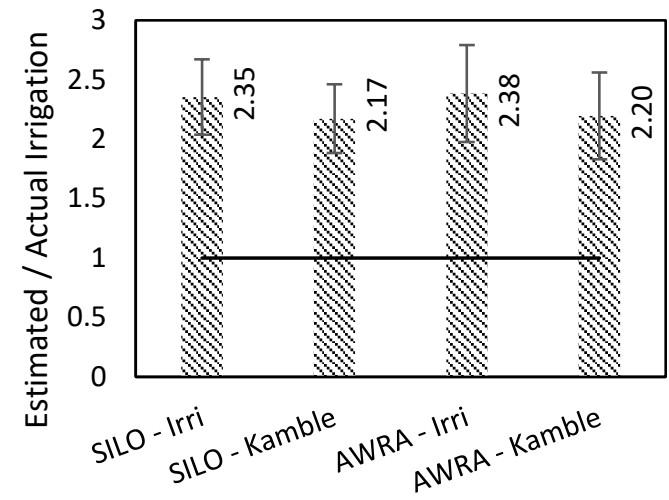

d)

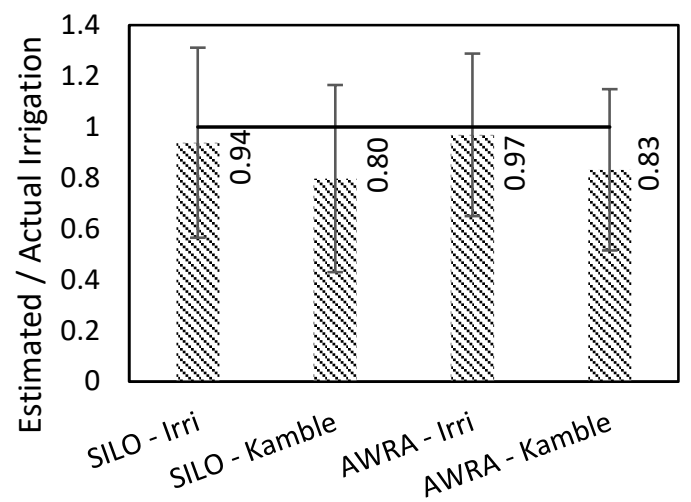

Figure 2. Ratio of estimated irrigation to observed irrigation for a) almond, b) wine grape 1, c) wine grape 2 and d) cotton. Error bars show \pm 1 standard deviation, with the black line showing where a ratio of 1 occurs. Values to the right of the column show the ratio value. 
The ratios presented in Figure 2, show very similar results when comparing the two products. The wine grapes 2 and cotton simulations produced a better ratio comparison using AWRA. This is despite the wine grapes 2 site having the closest average wind speed to the assumed $2 \mathrm{~m} / \mathrm{s}$. This is an indication that even with an average wind speed relatively similar; the temporal changes that occur throughout the year may not be causing inaccurate irrigation simulations. Alternatively, if annual local averages were incorporated into the derivation of the $E T_{0}$ product, simulations would likely improve (Jabloun and Sahli, 2008), as recommended by Allen et al. (1998). The slightly lower standard deviation seen when using the AWRA product indicates a more precise simulation.

The RMSE in Table 2 shows the AWRA product out performing SILO for crops that use the FAO56 short crop $E T_{0}$ (wine grapes and cotton), whereas the almond plantation, which uses the ASCE tall crop $E T_{0}$, shows better simulations using the SILO derived $E T_{0}$. In the case of the almond plantation, model overestimation caused by small errors may be counteracting the SILO underestimations to create these better results. The differences seen in the wine grapes 1 and 2 locations is relatively low, while cotton and almond see bigger changes. The magnitude of change seen in the almond field is somewhat negligible (at maximum 10\%) as the annual irrigation depth is much higher than for the cotton field (923 mm to $363 \mathrm{~mm}$ ). Additionally, the effects of wind speeds on irrigation simulations may differ depending on the crop types and how this vegetation interacts with the atmosphere.

On a yearly scale there is a noticeable difference between the two remote sensing relationships while using the same $E T_{o}$. This is something that will be looked into during future work to identify a best solution. The differences between the SILO and AWRA products compared here may also be affected by interpolation techniques, which has not been addressed in this paper.

Table 2. Irrigation depth RMSE (mm) of study sites, with best simulations shaded and in bold.

\begin{tabular}{ccccc}
\hline Crop & SILO - Irri & SILO - Kamble & AWRA - Irri & AWRA - Kamble \\
\hline Almond & $143.61(26.01)$ & $\mathbf{9 6 . 2 0}(\mathbf{2 3 . 5 9 )}$ & $182.21(29.62)$ & $130.83(26.22)$ \\
Wine Grape 1 & $181.17(25.75)$ & $157.41(23.54)$ & $177.93(24.82)$ & $\mathbf{1 5 3 . 8 9}(\mathbf{2 2 . 5 4 )}$ \\
Wine Grape 2 & 123.83 & 80.51 & 111.53 & $\mathbf{7 3 . 9 9}$ \\
Cotton & 128.08 & 155.54 & $\mathbf{1 0 8 . 1}$ & 134.79 \\
\hline
\end{tabular}

\section{CONCLUSION}

The two gridded products compared in this paper both simulate irrigation relatively similarly. The major differences of simulated irrigation between products was observed during high irrigation months, which is predominately caused by hot, dry and windy conditions causing higher evapotranspiration rates. At these times, it is likely that the climate derived wind speeds used in the AWRA products are closer to the actual wind speeds as discussed previously. The assumed $2 \mathrm{~m} / \mathrm{s}$ wind speed used by SILO may provide good results in regions with speeds closer to the assumption, although temporal changes may negatively affect these simulations. The results in this paper show marginally better simulations of irrigation depth using AWRA over the two vineyards and the cotton field, while the standard deviation was decreased using AWRA over all the sites tested. The differences observed when using the two products were small, although AWRA seemingly shows a more accurate estimation of irrigation simulation for the sites tested.

Generally, the method used for irrigation simulation is still subject to some errors, which may be affecting the accuracy of actual irrigation depth values. Despite these potential errors, this work still provides evidence to recommend the AWRA gridded product for applications that rely on wind speed accuracy due to a lower relative error for most cases observed in this paper.

\section{ACKNOWLEDGEMENTS}

The authors would like to acknowledge the South Australian Research and Development Institute (SARDI) for sharing the irrigation observation data for two of the sites used in this study. David Bretreger is supported by an Australian Government Research Training Program Scholarship. 


\section{REFERENCES}

Allen, R.G., Pereira, L.S., Raes, D., Smith, M., 1998. Crop evapotranspiration - Guidelines for computing crop water requirements - FAO Irrigation and drainage paper 56. Food and Agriculture Organization, Land and Water, Rome, Italy.

Beesley, C.A., Frost, A.J., Zajaczkowski, J., 2009. A comparison of the BAWAP and SILO spatially interpolated daily rainfall datasets, 18th World IMACS / MODSIM Congress, Cairns, Australia.

Bretreger, D., Quijano, J., Awad, J., 2018. Monitoring Irrigation Volumes using Climate Data and Remote Sensing Observations, 38th Hydrology and Water Resources Symposium (HWRS 2018): Water and Communities. Engineers Australia, Melbourne, Australia, pp. 112-123.

Bretreger, D., Yeo, I.-Y., Quijano, J., Awad, J., Hancock, G., Willgoose, G., 2019. Monitoring irrigation water use over paddock scales using climate data and landsat observations. Agricultural Water Management 221, 175-191.

Córdova, M., Carrillo-Rojas, G., Crespo, P., Wilcox, B., Célleri, R., 2015. Evaluation of the Penman-Monteith (FAO 56 PM) Method for Calculating Reference Evapotranspiration Using Limited Data. Mountain Research and Development 35, 230-239.

Dhu, T., Dunn, B., Lewis, B., Lymburner, L., Mueller, N., Telfer, E., Lewis, A., McIntyre, A., Minchin, S., Phillips, C., 2017. Digital earth Australia - unlocking new value from earth observation data. Big Earth Data 1, 64-74.

Frost, A.J., Ramchurn, A., Oke, A., 2017. Daily gridded evapotranspiration estimates for Australia, 22nd International Congress on Modelling and Simulation. MODSIM, Hobart, Tasmania, Australia.

Frost, A.J., Ramchurn, A., Smith, A., 2018. The Australian Landscape Water Balance model (AWRA-L v6). Bureau of Meteorology, Australia.

Frost, A.J., Wright, D.P., 2018. The Australian Water Resource Assessment Landscape model - AWRA-L: improved performance and regional calibration, 38th Hydrology and Water Resources Symposium (HWRS 2018): Water and Communities. Engineers Australia, Melbourne, Australia, pp. 933-949.

Hornbuckle, J., Jamie, V., Carlos, B., Janelle, M., Robert, H., Robert, B., 2016a. IrriSAT Technical Reference. Deakin University, CSIRO Land \& Water, NSW DPI, Australia.

Hornbuckle, J., Montgomery, J., Vleeshouwer, J., Hoogers, R., Ballester, C., 2016b. Using the Irrisat App to improve on-farm water management, Irrigation Australia International Conference, Melbourne Convention \& Exhibition Centre.

Jabloun, M., Sahli, A., 2008. Evaluation of FAO-56 methodology for estimating reference evapotranspiration using limited climatic data. Agricultural Water Management 95, 707-715.

Jeffrey, S.J., Carter, J.O., Moodie, K.B., Beswick, A.R., 2001. Using spatial interpolation to construst a comprehensive archive of Australian climate data. Environmental Modelling \& Software 16.

Jones, D.A., Wang, W., Fawcett, R., 2009. High-quality spatial climate data-sets for Australia. Australian Meteorological and Oceanographic Journal 58, 233-248.

Kamble, B., Kilic, A., Hubbard, K., 2013. Estimating Crop Coefficients Using Remote Sensing-Based Vegetation Index. Remote Sensing 5, 1588-1602.

McVicar, T.R., Van Niel, T.G., Li, L.T., Roderick, M.L., Rayner, D.P., Ricciardulli, L., Donohue, R.J., 2008. Wind speed climatology and trends for Australia, 1975-2006: Capturing the stilling phenomenon and comparison with near-surface reanalysis output. Geophysical Research Letters 35.

Pendergast, L., Bhattarai, S.P., Midmore, D.J., 2013. Benefits of oxygation of subsurface drip-irrigation water for cotton in a Vertosol. Crop \& Pasture Science 64, 1171-1181.

Phogat, V., Skewes, M.A., McCarthy, M.G., Cox, J.W., Šimůnek, J., Petrie, P.R., 2017. Evaluation of crop coefficients, water productivity, and water balance components for wine grapes irrigated at different deficit levels by a sub-surface drip. Agricultural Water Management 180, 22-34.

Pitt, T., Cox, J., Phogat, V., Fleming, N., Grant, C., 2015. Methods to increase the use of recycled wastewater in irrigation by overcoming the constraint of soil salinity. South Australian Research and Development Institute (SARDI), Adelaide, South Australia.

Rouse, J.W., Haas, R.W., Schell, J.A., Deering, D.H., Harlan, J.C., 1974. Monitoring the vernal advancement and retrogradation (Greenwave effect) of natural vegetation. NASA/GSFC, Greenbelt, MD, USA.

SILO, 2016. SILO Data formats. Queensland Government, Brisbane, QLD, Australia.

Tozer, C.R., Kiem, A.S., Verdon-Kidd, D.C., 2012. On the uncertainties associated with using gridded rainfall data as a proxy for observed. Hydrology and Earth System Sciences 16, 1481-1499.

Trout, T.J., Johnson, L.F., 2007. Estimating Crop Water Use From Remotely Sensed NDVI, Crop Models, and Reference ET, USCID 4th International Conference on Irrigation and Drainage, Sacramento, California, pp. 275-285. 